\title{
VARIABLE EMISSIVITY THROUGH MEMS TECHNOLOGY
}

\author{
Ann Garrison Darrin, Robert Osiander and John Champion', \\ Ted Swanson and Donya Douglas', and Lisa M. Grob ${ }^{3}$ \\ ${ }^{1}$ The Johns Hopkins University Applied Physics Laboratory, 11100 Johns Hopkins Road Laurel, MD 20723 \\ ${ }^{2}$ NASA Goddard Space Flight Center, Thermal Branch, Greenbelt, MD, 20771 \\ ${ }^{3}$ Swales Aerospace, Beltsville MD 20705
}

\begin{abstract}
This paper discusses a new technology for variable emissivity (vari-e) radiator surfaces, which has significant advantages over traditional radiators and promises an alternative design technique for future spacecraft thermal control systems.
\end{abstract}

All spacecraft rely on radiative surfaces to dissipate waste heat. These radiators have special coatings, typically with a low solar absorptivity and a high infrared-red emissivity, that are intended to optimize performance under the expected heat load and thermal sink environment. The dynamics of the heat loads and thermal environment make it a challenge to properly size the radiator and often require some means of regulating the heat rejection rate of the radiators in order to achieve proper thermal balance. Specialized thermal control coatings, which can passively or actively adjust their emissivity offer an attractive solution to these design challenges. Such systems would allow intelligent control of the rate of heat loss from a radiator in response to heat load and thermal environmental variations. Intelligent thermal control through variable emissivity systems is well suited for nano and pico spacecraft applications where large thermal fluctuations are expected due to the small thermal mass and limited electric resources.

Presently there are three different types of vari-e technologies under development: Micro EloctroMechanical Systems (MEMS) louvers, Electrochromic devices, and Electrophoretic devices. This paper will describe several prototypes of micromachined (MEMS) louvers and experimental results for the emissivity variations measured on theses prototypes. It will further discuss possible actuation mechanisms and space reliability aspects for different designs. Finally, for comparison, parametric evaluations of the thermal performances of the new vari-e technology and standard thermal control systems are also presented in this paper.

\section{KEY WORDS : Satellite, Thermal Control, Microtechnology}

\section{NOMENCLATURE}

$$
\begin{array}{ll}
-Z & \text { zenith radiator } \\
+Z & \text { nadir side radiator } \\
+Y & \text { cold side radiator } \\
\text { Greek symbols } \\
\alpha=\text { absoptivity } \\
\square=\text { emissivity }
\end{array}
$$

\section{INTRODUCTION}

All spacecraft and the instruments they support require an effective thermal control mechanism in order to operate as designed and achieve their expected lifetimes. In an increasing number of satellites, optical alignment and calibration require a strict temperature control. Traditionally, the thermal design is part of the spacecraft layout determined by all subsystems and instruments. Heat load levels and their location on the spacecraft, equipment temperature tolerances, available power for heaters, view to space, and other such factors are critical to the design process. Smaller spacecraft with much shorter design cycles and fewer resources such as heater power, volume, and surface, require an active approach. Commonly used active methods such as electric make-up heaters, heat pipes or mechanical louvers incur additional electric power requirements, weight, and bulkiness to the system. New, more flexible approaches are desined to address these concerns. One solution is a radiator coating with a variable infrared emissivity which can actively be adjusted in response to variations in load and environmental conditions. Such 
variable emissivity thermal control coatings, which include electrochromic and electrophoretic devices, have been under development at NASA-Goddard Space Flight Center (GSFC) since the mid-1990's. More recently, a new technique has been investigated in which micromachined mechanical louvers can be opened or closed to vary the emissivity of a radiator surface. (Champion 1999) While very similar to macro scale louvers, current micromachining techniques allow for fabrication of devices with feature sizes on the order of micrometers (Gilmore 1994, Helvajian 1997). These micro louvers can be fabricated on suitable substrates and used in place of traditional radiators.

\section{MEMS LOUVER DESIGN AND FABRICATION}

Micro-electro-mechanical (MEMS) louvers are similar in design to traditional macroscopic louvers in that they can be opened or closed to expose an underlying high emissivity radiator. Their small size, a few hundreds of micrometers, allows for different mode of operation. They area attached to the radiator surface and do not add substantial weight or bulk to the spacecraft. The large number of louvers, which ideally can be actuated independently, also allows control of the number of open and closed louvers and does not require any intermodiate position. Three different MEMS designs have been investigated and fabricated. The three designs are depicted in Figure 1, showing each prototype in the open and closed position. The simplest design is a louver that can be opened to a vertical position to expose an area of the high emissivity substrate to space. In a second design, multiple levels of sliders move across each other. In this case, the total area, which can be exposed, depends on the number, $n$, of layers available in the fabrication process and is about $(1-1 / n)$ times the slider area.. Advantages of this approach include the twodimensional design, the linear variability of exposed area, and the sturdiness of the design. The thind prototype mimics a bi-fold door. This design is more complicated than the other two since it uses more hinges, but we expect it to be more nugged than the single louvers while providing the same active area. Preliminary experience has shown that these devices are less likely to break during release and operation. The MEMS prototypes have been designed at the Applied Physics Laboratory (APL), fabricated at the MCNC Technology Applications Center using the MCNC Multi-User MEMS Process (MUMPs), and subsequently released and tested at APL. The base material for the current devices is polysilicon and the exposed, top surface is coated with gold, which has a very low emissivity of 0.02 . For the section of the silicon chip, which underwent emissivity testing, the silicon substrate under the louvers has been removed using deep reactive ion etching (DRIE). Figure 2 shows images taken from videos of the prototypes for each design when actuated. in the closed, semi-open, and open position. Figure 3 is a visible image of a louver array closed, and with some louvers open. Where the louvers are open, the background can be seen through the etch holes.

\section{EMISSIVITY MEASUREMENTS}

Infrared images taken at room temperature allow for a reasonable estimate of the performance of the louvers to be made. The die containing the louvers was mounted onto a radiator held at $40^{\circ} \mathrm{C}$. Infrared images in the wavelength range between $2.5 \mu \mathrm{m}$ and $5 \mu \mathrm{m}$ were taken with an Amber Radiance Infrared Camera. Using a close-focus attachment, the resolution was on the order of $10 \mu \mathrm{m}$ per pixel. Calibration was performed on a window etched in the substrate showing the radiator, $($ emissivity $=1)$ and on a gold-coated area (emissivity = 0.02 ) of the substrate. Suggest deletims this next sentence.seems to conflict with the $(x), 02$ of above - Vapor deposited gold has an absorption efficiency of 19-3 and an enissivity rating of .03-1. .-- Images of the calculated emissivities of the MEMS louvers are shown in Figure 4 for different numbers of closed louvers together. The louvers were opened manually using a probe tip. The average emissivity, $\varepsilon$, for the louver area is 0.5 for the number $\mathbf{n}=0$ of open louvers, 0.75 for $n=6$, and 0.88 for $n=12$, respectively. Note that a sizeable fraction of the area over which this measurement was made is devoted to mechanical structures supporting the device operation Through design modifications, we believe that the ratio of louver area to support structure area can be increased, which would increase the variation in effective emissivity up to the order of eighty percent.

\section{LOUVER ACTUATION}

For a successful application of the MEMS louvers for spacecraft thermal control, an actuation mechanism has to be identified which allows a high level of individual control, rugged operation, and a minimum of space. Note that the area covered by the actuator rectuces that available to the vari-e radiator and presents an emissivity bias. Highly individual louver control provides the best accuracy in setting the emissivity and further allows increased control of the spatial emissivity variations and operational rectundancy. Further, low power consumption and zero power in a static condition are required for small spacecraft applications. Several actuation mechanisms have been investigated including 

an electrostatic comb drive. While this standard MEMS actuator is a low power and reliable device, the large area required and from a space-craft perspective, the relatively high driving voltages (tens of volts) necessary, and the tendency of a coating exposed to the space environment to huild up a static charge. are limitations. Another mechanism, a "heatuator"(Butler, 1999), which occupies less area on the die has also been investigated with prototype louvers. It does not require high voltages but will consume power in the form of current to heat the actuator structure. Similarly, other actuation mechanisms which involve thermal expansion, including paraffin actuators, bimetallics or shape-memory alloys such as Nitanol $^{\mathrm{TM}}$ (Seguin, 1999) require current for the actuation Therefore, the design will ensure that current is only required to change the emissivity.

\section{RELIABILITY ASPECTS}

No discussion of the use of MEMs in critical space flight would be complete with out mentioning the unique concerns specific to MEMs. The louvers must survive through the launch and operate in the harsh environment of space. In addition, the effects of pre-launch storage must also be taken into consideration. A non-exhaustive list of the of MEMS reliability concerns includes: stiction, wear, fatigue, contamination, and radiation effects. (Stark, 1999).

Although stiction has not been observed in the prototype devices, the MEMS louvers are probably susceptible to this failure mechanism as a result of electrostatic interactions, capillary forces, or even localized cold welding (Patton, 1999). These concerns can be addressed in several ways. For example, proper ground design should minimize the potential mechanical seizure due to electrostatic clamping Excessive condensation of moisture, especially during pre-launch storage, can be mitigated through the use of hydrophobic coatings and outgassing techniques. Furthermore, appropriate packaging could be employed to prevent the accumulation of water and other contaminants on critical surfaces of the devices.

While relative humidity (RH) levels in excess of $70 \%$ have been associated with been degraded mechanical performance attributed to increased stiction, elevated frictional wear between contacting parts has been observed in extremely low RH environments (Tanner, 1999). Due to the negligible $\mathrm{RH}$ of the intended operational environment, the possible degradation of the hinge joints over the device lifetime is an important issue. Minimum lifetimes will be on the order of 10,000 to 50,000 cycles. Various coatings and design modifications to minimize friction are being considered. Similarly, the effects of fatigue on hinges and actuators are also being examined Finally, in a space environment, the MEMS louvers will be subjected to high-energy irradiation. As a result, charge buildup in dielectric layers could occur which may lead to inconsistent or degraded operation of either the louvers or electrostatic actuators.

\section{PARAMETRIC ANALYSES}

An incremental study approach was used to progressively assess the thermal performance of different vari-e raciators (Grob, 2000). The orbits and environments used in all phases of the study were selected to reflect the TERRA spacocraft design, with specific emphasis on the spacecraft's batteries. TERRA's orbit is a sun-synchronous 10:30 descending node, $98.2^{\circ}$ inclination polar orbit at an altitude of 705 $\mathrm{km}$. For the dynamic study, TRASYS and SINDA Thermal Math Models (TMMs) of a simplified cube provided heater power requirements for the zenith, nadir and cold side radiators surfaced with traditional and varie coatings. The parameters used in the transient analysis are listed in Table 1. Temperature set points of the proportional heater modeled in SINDA, were set below the vari-e light to dark set point in an attempt to minimize the number of cycles the variable emissivity surfaces would experience. Of particular interest are the spacecraft "cold side" $(+Y)$ radiators where most of the housekceping equipment (including the nickel hydrogen batteries) resides and the instrument dock on the nadir side $(+Z)$ for the typical LEO science mission. Both the nadir and cold side radiators experience mainly albedo and IR fluxes. The albedo is significant, however, in the low beta orbits. During the year, the TERRA spacecraft has a beta range of $13^{\circ}$ to $32^{\circ}$. The zenith $(-Z)$ radiator was also studied since a significant portion of the TERRA housekeeping equipment is accommodated there. The zenith radiator experiences direct solar fluxes, which emphasizes the significance and/or limitations of the current vari-e technologies' absorptivities. The transient results from the simple cube model are listed in Tables 3. Note, the effects of the UV environment and radiator absorptivity on some of the radiators. On all vari-e-radiators, the heater savings are in the order of $60 \%$ to $80 \%$ compared to the fixed radiators. In an additional calculation modeling the TERRA batteries with an MEMS battery radiator the orbital average heater power savings was 54 watts, essentially all the power needed for the batteries to maintain their minimum allowable temperature in the original configuration. In all 

TABLE 1. Transient Analysis Assumptions and Parameters.

Typical sun-synchronous LEO orbit /
beta range $13^{\circ}$ and $32^{\circ}$
Hot Case Models:
EOL environment and properties on all cube surfaces, Panel
temperatures maintained $\left(a, 30^{\circ} \mathrm{C}\right.$
Cold Case Models
BOL environment and properties on all cube surfaces, Panel
temperatures maintained $(a)-10^{\circ} \mathrm{C}$
Set Points:
$-8^{\circ} \mathrm{C}$ to $-10^{\circ} \mathrm{C}$ for proportional heater
$-5^{\circ} \mathrm{C}$ for vari-e surfaces

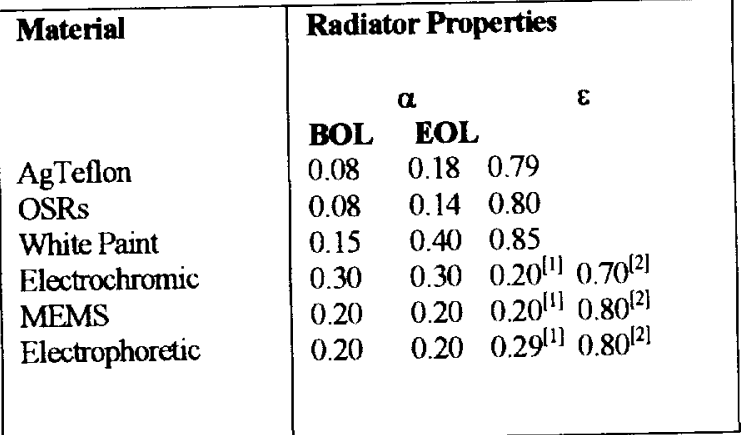

[1] light/closed/activated state [2] dark/open/base state

TABLE 2. Results for orbital average heater power [W] from transient cube model for different radiator positions

\begin{tabular}{|c|c|c|c|c|c|c|}
\hline Orbit & Ag Tefion & $\overline{\text { OSRs }}$ & White Paint & $\begin{array}{l}\text { Electro- } \\
\text { chromics }\end{array}$ & $\begin{array}{l}\text { Electro- } \\
\text { phoretics }\end{array}$ & MEMS \\
\hline \multicolumn{7}{|l|}{ Zenith Radiator } \\
\hline $13^{\circ} \mathrm{EOL}$ & 32 & 37 & 28 & 9 & 10 & 6 \\
\hline Tmax $\sqrt{\text { Tave }}\left[{ }^{\circ} \mathrm{C}\right]$ & $-8 /-8$ & $-8 /-8$ & $44 / 5^{*}$ & $34 / 3^{*}$ & $0 /-6$ & $0 /-6$ \\
\hline $32^{\circ} \mathrm{BOL}$ & 43 & 44 & 41 & 10 & 10 & 7 \\
\hline Tmax Tave $\left[{ }^{\circ} \mathrm{C}\right]$ & $-8 /-8$ & $-8 /-8$ & $-8 /-8$ & $19 /-2^{*}$ & $-5 /-7$ & $-5 /-7$ \\
\hline \multicolumn{7}{|l|}{ Nadir Radiator } \\
\hline $13^{\circ} \mathrm{EOL}$ & 10 & 11 & 6 & 2 & 2 & 1 \\
\hline Tmax/Tave $\left[{ }^{\circ} \mathrm{C}\right]$ & $-8 /-8$ & $-8 /-8$ & $4 /-5$ & $1 /-5$ & $-4 /-6$ & $-4 /-6$ \\
\hline $32^{\circ}$ BOL & 14 & 14 & 13 & 2 & 2 & 1 \\
\hline Tmax Tave $\left[{ }^{\circ} \mathrm{C}\right]$ & $-8 /-8$ & $-8 /-8$ & $-8 /-8$ & $0 /-6$ & $-4 /-7$ & $-4 /-8$ \\
\hline \multicolumn{7}{|c|}{$\begin{array}{l}\text { Imax lave [C] } \mid--8 /-8 \\
\text { Cold Side Radiator }\end{array}$} \\
\hline $13^{\circ} \mathrm{EOL}^{\star \star *}$ & 39 & 40 & 41 & 13 & 14 & 9 \\
\hline $32^{\circ} \mathrm{BOL}^{\star \star *}$ & 40 & 40 & 43 & 14 & 14 & 10 \\
\hline
\end{tabular}

* Elevated temperature due to higher $\alpha$ and non-optimized area

**Temperatures never go above heater set point temperatures 



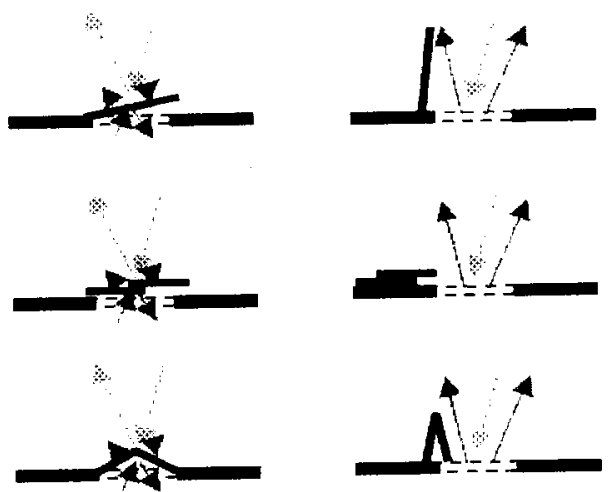

Fig. 1: Different design concepts for a thermal control structure: louver (top), slider (middle), and folder (bottom). 


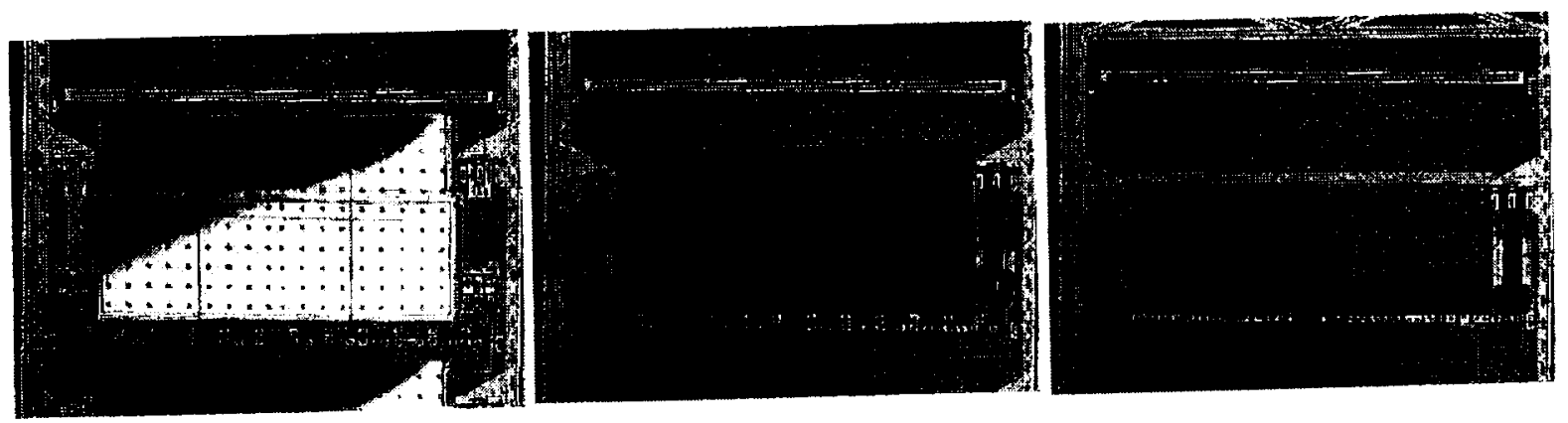

Fig. 2a: Images from video of MEMS louver opening

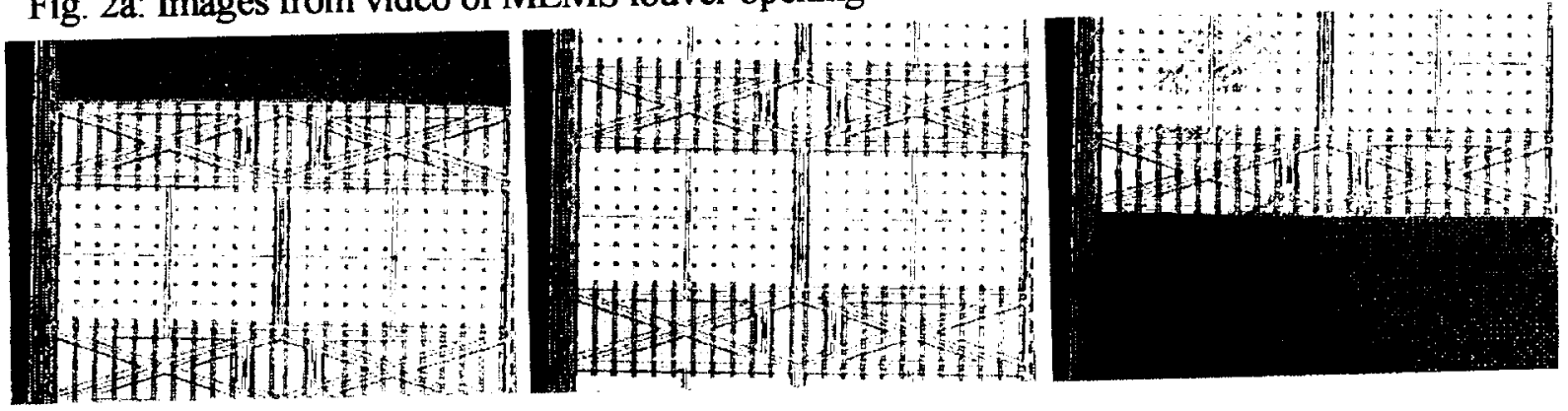

Fig. 2b: Images from video of MEMS slider opening
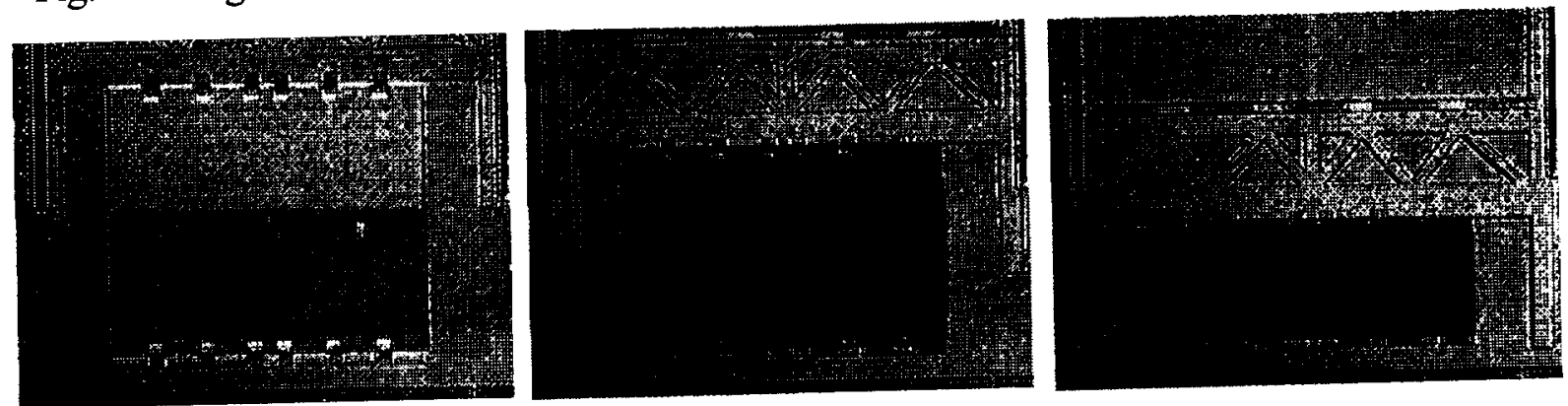

Fig. 2c: Images from video of MEMS folder opening
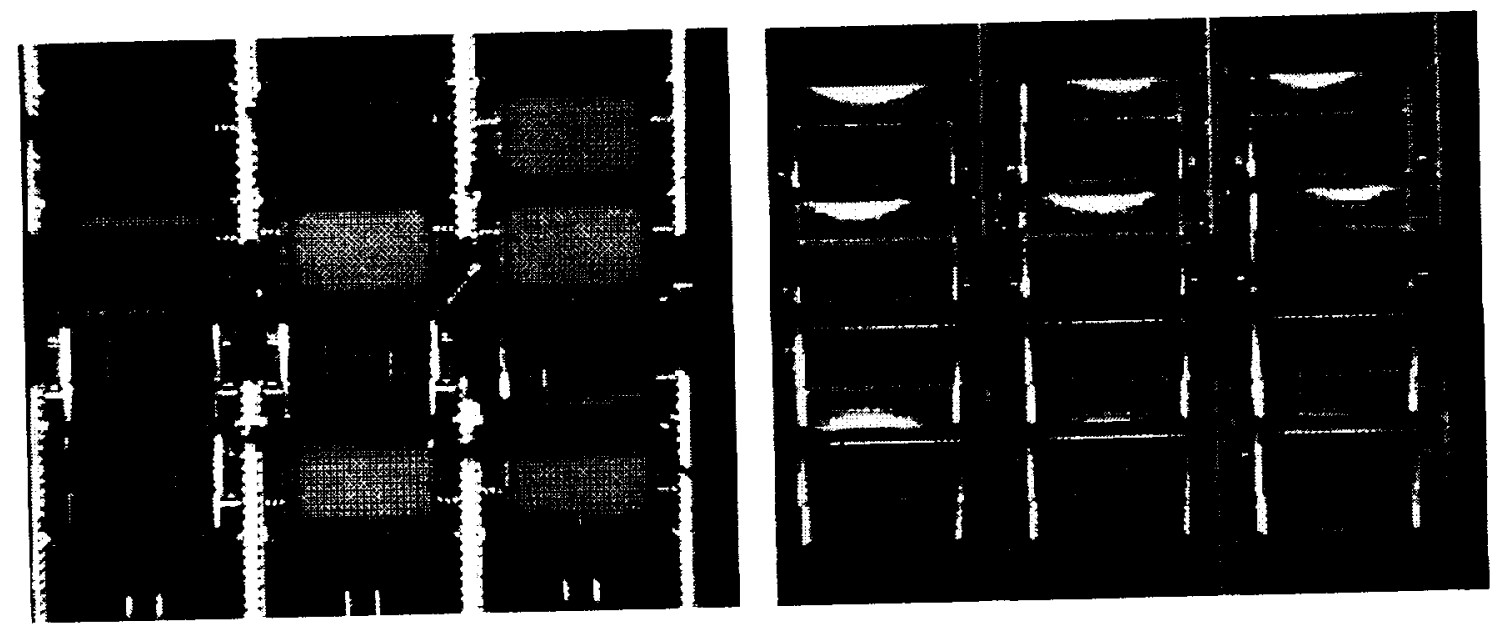

Fig. 3: Optical image of louver array, with open louvers (left) and all louvers closed (right). The open louvers expose the background through the etched openings. 



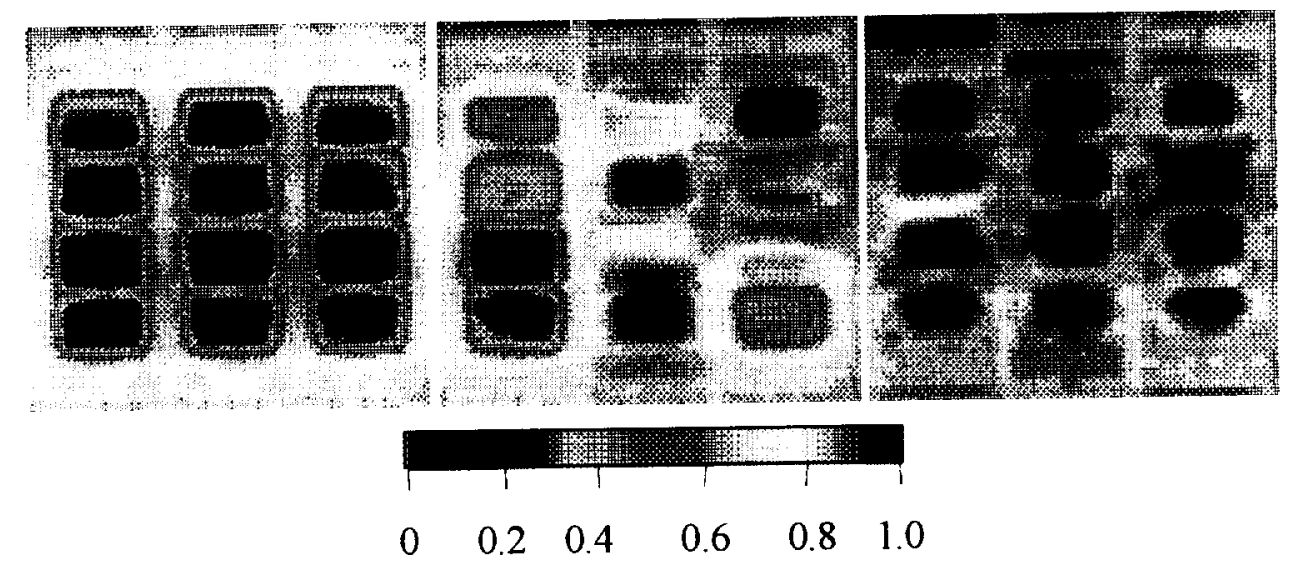

Fig. 4: Emissivity images of a louver array on a radiator $\left(40^{\circ} \mathrm{C}\right)$ with all louvers closed (left, average emissivity $\varepsilon=0.5$ ), partially open (center, $\varepsilon=0.75$ ), and all open (right, $\varepsilon=0.88$ ).

\section{CONCLUSHONS}

As illustrated throughout this study, vari-e technology offers significant advantages over current approaches for radiators in low UV environments. The heater power, mass, and cost savings that can be realized with these systems are potentially significant for many spacecraft design applications. For example, eliminating the TERRA battery heater power during on-orbit hot and cold cases by using a MEMs radiator demonstrated quite clearly the impact this technology may have on spacecraft design.

In order to make the benefits the most useful to all satellite radiating surfaces; a reduction in the vari-e's solar absorptivities is very desireable. Attention must also be paid to the vari-e maximum activation cycles, which may be the limiting factor for battery radiators and other dynamic dissipating systems. A rechuction of cycles can be achieved with the proper set point temperature selection and the additional variable switch (i.e. battery pressure, time). Numerous future NASA missions, such as the ST5 Nanosat Constellation Trailblazer, will undergo significant changes in its thermal environment and will require means of modulation in the spacecraft's heat rejection rate. Specifically, the Trailblazer spacecraft will undergo an approximately 2-hour or longer eclipse during which time the instruments must survive and possibly operate. Given their small capacity for power storage by batteries and low thermal capacitance, the best strategy will be to "close off" their radiator area and radically reduce their heat loss rate. The
MEMS lovers, together with two other variable emissivity technologies, have been chosen as a demonstration technology on NASA's New Millenium ST5 "Nanosat Constellation Trailblazer" mission. Each tochnology will control a $20 \mathrm{~cm} \times 6 \mathrm{~cm}$ radiator area on one of the three nanosats.

In addition to the obvious weight and power savings, the technology of MEMS louvers for thermal control will greatly simplify spacecraft design and qualification testing and also allow adaptive response to changing power levels or unexpected thermal environments once on-orbit. With the emerging capability to control emissivity, thermally tunable surfaces for space flight applications is becoming a reality.

\section{REFERENCES}

Butler, J.T., Bright, V.M, and Cowan, W. D., "Average power control and positioning of polysilicon thermal actuators," Sensors and Actuators 72, 1999, pp 88-97.

J. L. Champion, R. Osiander, M. A. Garrison Darrin, T. D. Swanson, "MEMS Lowers for Thermal Controf", MNT99 Proceedings, pp 233-241, 1999.

Gilmore, D. G., Satellite Thermal Control Handbook, The Aerospace Corporation Press,El Segundo, CA, 1994. 
Helvajian, H., Janson, S.W. and Robinson, E. Y, "Big benefits from tiny technologies: Micro-nanotechnology applications in future space systems," Critical Reviews of Optical Science and Technology, Taylor, E.W., Ed, SPIE Vol. CR66, pp 22-23, 1997.

L.M. Grob and T.D. Swanson, "Parametric Study of Variable Emissivity Radiator Surfaces",

STAIF-2000 Proceedings, 2000.

Patton, S.T., Cowan, W.D., and Zabinski, J.S., "Performance of a New MEMS Electrostatic Lateral Output Motor," IEEE IRPS Proc., pp 179-188, 1999.

Seguin, J.L., Bendahan, M., Isalgue, A., Esteve-Cano, V., Carchano,m H., and Torra, V., "Low temperature crystallized Ti-rich NiTi shape memory alloy films for microactuators" Sensors and Actuators 74, 1999, pp 6569.

Stark, B., Ed, MEMS Reliability Assurance Guidelines For Space Applications, JPL Publication 99-1, 1999.

Tanner, D.M, Walraven, J.A., Irwin, L.W., Dugger, M.T., Smith, N.F., Eaton, W.P., Miller W.M., and Miller, S.L., "The Effect of Humidity on the Reliability of a Surface Micromachined Microengine," IEEE IRPS Proc., 1999, pp 189-197.

Wolfe, W.L., and Zissis, G.J., Eds., The IR Handbook, Office of Naval Research, Dept. of the Navy, Arlington, VA, 1985. 
